Bol. Acad. peru. leng. 49. 2010 (135-147)

\title{
LENGUAS, APELLIDOS E IDENTIDAD EN EL PERÚ
}

\author{
Ofelia Huamanchumo de la Cuba \\ Ludwig-Maximilians-Universität München
}

Fecha de recepción:

$20 / 11 / 2009$

Fecha de aceptación:

$02 / 01 / 2010$

0. La Antroponimia es una de las ramas menos atendida de la Onomástica en los estudios de las ciencias humanas en el Perú, a pesar de que, tanto como la Toponimia -sobre la que sí existen significativos estudios-, puede proporcionar no sólo datos decisivos para la Lingüística histórica, sino complementar los fundamentos de otras disciplinas que investiguen las interrelaciones entre cultura y sociedad. Esta nota pretende así animar los estudios en esa dirección y aperturar nuevas perspectivas en el debate respecto al rol que cumplen las lenguas en la construcción de las identidades nacionales.

\section{A la luz de un ejemplo concreto}

El nombre a analizar es un apellido de claro origen prehispánico: 'Huamanchumo', en torno al cual se tiene una documentación significativa, como es el caso de muchos otros apellidos peruanos, cuyos orígenes y transformaciones lingüísticas se prestarían a una investigación seria. 
1.1 En primer lugar, se tiene un indicio muy esclarecedor: el apellido peruano que quiero estudiar es actualmente un nombre propio poco común en el territorio del Perú; la mayoría de familias peruanas que lo lleva es de ascendencia trujillana, de la capital del departamento de La Libertad, y oriunda del distrito costeño de Huanchaco, con sus pescadores que hasta hoy conservan la tradición de las balsas conocidas como 'caballitos de totora'. Este dato facilita el inicio de la revisión bibliográfica, pues remite rápidamente a una zona con un pasado significativo en la historia del Perú.

1.2 Se sabe que muchos de los cronistas de los siglos XVI y XVII coincidieron en afirmar que sobre la actual ciudad de Trujillo, en la costa norte del Perú, existió el Reino Chimú, que ejerciera señorío desde su capital Chan-Chan. Así, por ejemplo, Pedro Cieza de León escribe: "[1553]: el valle de Chimo, ancho y muy grande, y adonde está edificada la ciudad de Trujillo. Cuentan algunos indios que antiguamente, antes que los Inkas tuviesen señorío, hubo en este valle un poderoso señor a quien llamaban Chimo, como el valle se nombra agora..." (1985: 278); mientras que Miguel Cabello Valboa afirma: "[1586]: ...y los Yndios yungas (que ansi llaman a los que habitan en tierras calientes y llanos de este Piru) porque en el valle de Chimo estaba un importuno contendor de sus disinios llamado Chimo Capac..." (1951:319) y el Inca Garcilaso de la Vega: "[1609]: ...un gran señor llamado Chimu, que era señor de los valles que hay pasada la barranca hasta la ciudad que llaman Trujillo" (1980: II, 183).

Por su parte, en estudios más modernos, Eugen F. Mayer menciona nombres encontrados en distintos mapas referidos al lugar en cuestión: "Candia [1535], Canchan [1536], Chimo [1572], Chanchan [1620], Cymor [1644], Chanchan [1763], etc.” (1982:3). Gracias también a las investigaciones realizadas por Ernst W. Middendorf se puede señalar que la actual ciudad de Trujillo era la que llevaba aquel nombre chimú, pues en el pueblo de Etén -la única población que hasta inicios del siglo XX conservó su antigua lengua aborigen ${ }^{1}-$ se seguía llamando chimorr a la

$\overline{1}$ Según un testimonio recogido por el antropólogo Carlos Dávila Herrera en su artículo "Presencia y Vigencia Mochicas" (2001) la lengua mochica que aún se hablaba en Etén 
ciudad de Trujillo, "de donde se ha formado la palabra chimú debido a la pronunciación descuidada de los españoles” (1959: 122).

1.3 Sobre los orígenes históricos de aquel Reino Chimú se conoce lo que un único autor dejara en su Crónica anónima de 1604-1610, donde se mencionan los antropónimos de algunos gobernantes:

$1^{\circ}$ Tacaynamo.

$2^{\circ}$ Guacri Caur (hijo de Tacaynamo).

$3^{\circ}$ Nañcenpinco (hijo de Guacri Caur).

$4^{\circ}, 5^{\circ}, 6^{\circ}, 7^{\circ}, 8^{\circ}, 9^{\circ}$ y $10^{\circ}$ (gobernante sin nombre citado).

$11^{\circ}$ Minchançaman (ocurre la Invasión Incaica).

$12^{\circ}$ Chumun Caur (hijo de Michançaman y Chanquirguanguan, su madre, hija de Topac Yupanqui).

13 Guaman Chumu (“...este Chumun caur tubo un hijo llamado Guaman Chumu...” / ocurre la Invasión Española).

$14^{\circ}$ Ancocoyuch ( "...lo sucedió Ancocoyuch, su hijo...").

$15^{\circ}$ Caja Cimcim (hermano del anterior; también Martín Caja Cimcim).

$16^{\circ}, 17^{\circ}, 18^{\circ}, 19^{\circ}, 20^{\circ}$ Caciques coloniales (no se da nombres).

21 $1^{\circ}$ Antonio Chayguar (1604), ("Don Antonio Chayguar que oy vive y es cacique deste valle de Chimor”), (Kauffmann Doig 1979: 438).

La lectura detenida de estos datos permite subrayar dos puntos. Primero, el hecho de que se señalen los primeros tres gobernantes sobre una base mítica tiene su explicación en la intención de legitimar un origen legendario como verídico. Segundo, el vacío de información entre el cuarto y el décimo descendiente se explica por el afán de legitimar también el paso de información de datos míticos a datos concretos, basados en la historia, conservada a través de diferentes medios mnemotécnicos, de los indígenas que lo narraron al cronista durante la primera década del siglo XVII, fecha en que se registran los datos.

en las primeras décadas del siglo XX "parecía chino", de ahí que algunos postulen la influencia de las lenguas chinas en ciertos antropónimos de la costa norte del Perú: Xailón, Jaylón, Ayllón, Suyón o Zu-yón. 
Por otro lado, se observa que los incas conquistaron a los chimúes cuando Michançaman estuvo a la cabeza del Reino Chimú, a quien los incas -siguiendo sus propias costumbres- le obsequiaron una mujer de la realeza. Es así como se podría explicar que el siguiente gobernante chimú, Chumun Caur, no fuera denominado con el apelativo real de Inca, pues su parentesco con la cultura dominante incaica no era vía paterna. Chanquirguanguan, madre de Chumun Caur, debió ser hija ilegítima del Inca Túpac Yupanqui, ya que ella no llevaba el apelativo de Palla, sino que su nombre debía corresponder al de la provincia de donde era natural su madre o concubina del rey. Esto se deduce de las observaciones que hace el Inca Garcilaso de la Vega (1980: I, 68) sobre las costumbres de filiación ${ }^{2}$ y nombres prehispánicos, a las que añade:

Estos nombres y renombres daban a la descendencia de la sangre real por línea de varón, y en faltando esta línea, aunque la madre fuese pariente del Rey, que muchas veces daban los reyes parientas suyas de las bastardas por mujeres a grandes señores; más sus hijos y hijas no tomaban de los apellidos de la sangre real ni se llamaban Incas ni Pallas, sino del apellido de sus padres, porque de la descendencia femenina no hacían caso los incas (69).

Cuando ocurre la invasión española estaba a la cabeza del Reino Chimú el gobernante Guaman Chumu, cuyo nombre se someterá al vivo contacto con la lengua española, como se verá en el siguiente acápite.

2 Cabe señalar que los criterios de sucesión en los gobiernos prehispánicos no suponían el traspaso del poder de padres a hijos, lo cual al parecer sería extensivo a la asignación de los nombres, es decir, el apellido no siempre se heredaba; de ahí que se explique por qué el hijo del cacique Sebastián Guamán Chumo se pueda llamar don Rodrigo Cuajuchi todavía hacia 1679, como se menciona en el testamento de Antonio Chumbi Huamán, Principal del pueblo de San Salvador de Mansiche (Vega Cárdenas 2008). Esto podría tener relación con el apellido del $14^{\circ}$ gobernante, hijo de Guaman Chumu, cuyo nombre parece estar conformado de dos voces, según la transcripción de Kauffmann Doig: 'anco' y 'coyuch', la segunda de las cuales podría ser una variante de 'cuajuchi'. 


\section{En torno al nombre del cacique Guaman Chumu}

Según Ernst W. Middendorf, los chimú hablaron una lengua -quizás llamada por ellos muchik o lengua moche- distinta de la lengua oficial de los incas y del aimara, tanto en la fonética de muchas consonantes y vocales, así como en las formas gramaticales, la morfología y la sintaxis; los españoles, siguiendo la tradición inca, los apoderaron chimú, pero no se sabe si era el valle, o sus habitantes o el personaje real o curaca que los gobernaba cuando fueron atacados por los incas (1959: 122). Por otro lado, Cerrón-Palomino tras estudiar algunos aspectos externos de la lengua mochica (referentes a su localización geográfica, su designación, su correlación histórico - cultural y su filiación lingüística) llega a comprobar que entre los chimú existieron otras lenguas totalmente ajenas al mochica, como el quingman, expandida en Trujillo (1995: 23 - 49).

Sobre la naturaleza de los vocablos del nombre del cacique Guaman Chumu presentaré a continuación algunas hipótesis, partiendo de la idea de que este antropónimo está conformado -si respetamos la forma como aparece escrito en la Crónica Anónima de 1604-1610 - por dos vocablos: Guaman y Chumu.

2.1 El vocablo Guaman. Este primer vocablo es de claro origen quechua, lo cual puede explicarse debido al hecho de que cuando vivía el gobernante Guaman Chumo ya se había producido la invasión incaica y, por tanto, la expansión del quechua entre los nobles chimú. El vocablo Guaman se compone, si se sigue la morfología castellana, de dos sílabas: 'gua' y 'man'. La sílaba 'gua' conforma muchos antropónimos como topónimos del quechua registrados por los cronistas españoles. Por ejemplo, Betanzos en Suma y Narración de los Yngas ([1551] 1987) nombra a 'Mama Guaco' y 'Guanacaure', así como Sarmiento de Gamboa en su Historia de los Incas ([1572] 1942) nombra a 'Yaguar Guaca', 'Mama Guaco' y 'Guanacancha'; también Cabello Valboa en su Miscelánea Antártida ([1586]1951) escribe 'Yaguarguaca', 'Mamaguaco' y 'Guanacauri'; y el padre Acosta registra en la Historia Natural y Moral de las Indias 'Yaguarguaque' ([1590] 1962); sin embargo, el Inca Garcilaso de la Vega en sus Comentarios Reales de los Incas ([1609] 1980) registrará los mismos nombres con la ortografía 
que considerara correcta: 'Yahuar Huacac', 'Mama Ocllo Huaco' y 'Huanacauri', transcripción que justifica en su libro:

El nombre 'guano' se ha de escrebir 'huano', porque, como al principio dijimos, no tiene letra ' $\mathrm{g}$ ' aquella lengua general del Perú: quiere decir estiércol [...] Deste paso y de otros muchos que apuntaremos, se puede sacar lo mal que entienden los españoles ese lenguaje, y aun los mestizos, mis compatriotas, se van ya tras ellos en la pronunciación y en el escribir, que casi todas las dicciones que me escriben desta mi lengua y suya vienen españolizadas, como las escriben y hablan los españoles, y yo les he reñido sobre ello (1980: II, 174).

El mismo Inca Garcilaso de la Vega menciona ya el vocablo quechua huaman, refiriéndose a una clase de ave:

(1) "Hay halcones de muchas raleas; algunos se asemejan a los de acá y otros no; en común les llaman los indios 'huaman' ” (1980: III, 121).

(2) "...y otros tantos halconcillos, de los que por ser tan lindos, han traído muchos a España, y en ellas les llaman 'aletos' y en el Perú 'huaman' "(1980: III, 170).

Esto nos lleva a deducir que el vocablo quechua guaman del antropónimo en cuestión sería una variante del vocablo huaman.

2.2 El vocablo Chumu. De este vocablo no he encontrado registro alguno en forma autónoma en ningún documento colonial o crónica historiográfica, así como tampoco en ninguna lista, ${ }^{3}$ gramática o

3 El antropólogo Jorge Zevallos Quiñones dio a conocer topónimos y antropónimos en sus estudios sobre los cacicazgos de la costa norte, en ninguno de las cuales aparece el vocablo Chumu en forma independiente, sino sólo en los antropónimos de gente noble chimú: Huaman Chum (en el Cacicazgo de Huamán), Huaman Chumu (en el Cacicazgo de Mansiche), Huamanchumo (en el Cacicazgo de Moche y deVirú, antes Guañape), (Zevallos 1992). Sobre su significado no se sabe nada, cuestión que valdría observar bajo la acotación que hiciera el Inca Garcilaso de la Vega sobre el significado de los nombres de los nobles Incas 
vocabulario del quechua, aymara ni mochica. En su Arte de la lengua Yunga Fernando de la Carrera tampoco registra vocablo parecido o semejante ([1644] 1939).

Independientemente de la lengua sustrato que precediera al registro del vocablo Chumu por un cronista anónimo, es muy probable que fuera tomado de una de las lenguas prehispánicas de la costa norte y registrado bajo un criterio ortográfico español. Sobre su significado no se sabe nada, cuestión que podría entenderse extendiendo a la nobleza chimú la acotación del Inca Garcilaso respecto al significado de los nombres de la realeza inca, de las cuales dice: "no sé que signifiquen, porque son nombres de la lengua particular que los Incas tenían para hablar ellos entre sí, unos con otros, y no de la general que hablaban en la corte" (1980: III, 222).

En cuanto a la pronunciación de este vocablo se puede seguir también al Inca Garcilaso para encontrar una posible explicación a su transcripción. Si se toman en cuenta las críticas que hace el Inca Garcilaso de la Vega en sus Comentarios Reales de los Incas respecto de la mala pronunciación por parte de los españoles de la lengua general del Perú, se puede observar cierta tendencia entre los hablantes de español a aperturar, por ejemplo, la voz andina transcrita por Garcilaso como /cu/, hacia una hispanizada $/ \mathrm{co} /$, como muestran los siguientes ejemplos:

(a) No será razón dejar en olvido la yerba que los indios llaman cuca y los españoles coca, que ha sido y es la principal riqueza del Perú...”(1980: III, 109).

(b) Creo que el tigre se llama uturuncu, aunque el padre Maestro Acosta da este nombre al oso, diciendo otoronco, conforme a la corrotela española; no se cuál de los dos se engaña; creo que su Paternidad (III, 119).

(c) Hay otras aves que también se pueden poner con las de rapiña; son grandísimas; llámanles cúntur y los españoles cóndor (III, 121).

Por otro lado, ya Fernando de la Carrera había advertido en el Prólogo de su Arte que existía una vocal "que los indios tenían de más" y 
que faltaba en el abecedario, por lo cual él recurría al diptongo latino 〈æ⿱ $\rangle$ para representarla. Cerrón-Palomino observa que muchas de las voces que en la primera documentación de la lengua mochica (Rituale seu Manuale Peruanum [1607]) de Luis Gerónimo de Oré aparecen indistintamente con $\left.<_{\mathrm{O}}\right\rangle$ ó con $\langle\mathrm{u}\rangle$, Fernando de la Carrera las escribe en su Arte con $\langle æ\rangle$ :

Oré
çoputo
noputof
onuco
ñofun

\author{
Carrera \\ çæpæt 'tres' \\ nopætof 'son cuatro' \\ onæ 'uno' \\ ñofæn 'hombre' (Cerrón-Palomino 1995:77).
}

Por tanto, de todas estas observaciones se puede suponer que el vocablo Chumu se pronunciara como <chumæ> y que fuera registrado por algunos como /chumu/y por otros como /chumo/, hasta quedar en la última forma, como muestra también la tendencia en la pronunciación española de vocablos hispanizados de voces quechuas en los ejemplos citados.

A ello podría agregarse otra anotación del mismo Cerrón-Palomino respecto a que, dada la práctica ortográfica inaugurada por los lingüistas del Tercer Concilio Limense (1582 - 1583), afanados en elaborar un quechua general, se dejara sin representación autónoma a aquellos fonemas cuya notación requería de diacríticos especiales (1995: 78); observación que puede hacerse extensiva a una reducción que se produciría también en otras lenguas prehispánicas, como el caso del $\langle æ>$ del mochica o del quignam.

\section{Preservación de los apellidos prehispánicos}

La preservación de la dinastía chimú -y así, de los nombres de sus gobernantes y descendientes- no sólo fue posible por la política de tolerancia parcial frente a las culturas vencidas practicada por los incas, ${ }^{4}$

$\overline{4}$ Sobre la rendición del gran Chimú y la benevolencia del Inca vencedor, véase en 
sino porque la Corona española misma dictaminó, además, algunas leyes que permitirían la preservación de los beneficios de grandes señores de las culturas prehispánicas, como fue el caso de los 'caciques'. En 1557 una ley disponía que quienes en tiempos "de su infidelidad" habían sido Caciques, o Principales descendientes de ellos, no perdieran sus títulos, para no hacerlos de peor condición a causa de la llegada de la Religión Católica. Otra ley de 1576 disponía que sucedieran en los cacicazgos sólo los que fueran indios, y no mestizos (Recopilación [1971] 1943: 246), quizás para evitar que finalmente los caciques fueran despojados por españoles advenedizos o criollos.

Sumado a esto, un factor a favor aún más decisivo en la conservación de los antropónimos de los Caciques, de sus descendientes y de los indios de los repartimientos y encomiendas, fue el hecho de que la política económica española exigió registros del control económico de sus colonias. Ese aspecto se puede rastrear no sólo en la dación de leyes o disposiciones en torno (Instrucciones, ${ }^{5}$ Ordenanzas, Provisiones, etc.), sino en la aplicación de las mismas en la práctica (registros hechos en Visitas civiles, Tasas y Retasas de las encomiendas, etc.).

Así lo estipulará también el mismo Virrey Toledo en muchas de sus Ordenanzas dictadas entre 1569 y 1581, aunque, por otro lado, dictara a su vez otras implícitamente en contra de la preservación de los antropónimos prehispánicos:

Garcilaso el capítulo XXXIII del Libro Sesto: "Pertinencia y aflicciones del gran Chimú, y cómo se rinde" (1980: II, 185-187).

5 Francisco Pizarro muy tempranamente ya estipulaba en la Instrucción (del 4 de junio de 1540) que dio a Diego Verdejo para la Visita que había de hacerse desde Chicama hasta Túcome que se registraran los nombres de pobladores: "cada cacique de por si con sus indios e subjetos" y lugares de la región (Levillier 1921: I, 20). Lo mismo se observa en la Provisión en que se declara la orden que se ha de tener en las tassaciones que se han de hazer en los repartimientos de Indios, año de 1551: "Y ansi declarado lo que deven pagar, hagan un libro de los pueblos y pobladores y tributos que ansi declaraban" (Lafaye 1999: 176 - 177). 
Ordenanza XIII.- [...] Item, por cuanto los indios é indias ponen á sus hijos sobrenombres conforme á los ritos y agüeros que tenían en tiempo de su infidelidad y del Inga, poniendo á algunos de ellos sobrenombres de la Luna y otros pájaros, animales, piedras, sierpes y ríos, que cuando los paren sus madres, se les ofrece á la vista y memoria. Mando, que de aquí adelante no puedan poner sobrenombres á sus hijos, sino de los de sus padres, ó madres, ó abuelos, so pena que serán gravemente castigados ellos y los caciques que lo contrario hicieren: y encargo al sacerdote de la doctrina, que en ninguna manera lo consienta, y al corregidor de los naturales que los castigue (Levillier 1929: 365).

Por su parte, el Tercer Concilio Limense de 1583 prescribirá el seguimiento de los patrones de filiación occidentales, lo cual a la larga contribuirá a la extinción de muchos antropónimos en lenguas aborígenes:

Capítulo 11: De los nombres de los indios. Para que no se cometan demasiadas equivocaciones con el bautismo y el matrimonio al repetirlos indios desconocidos, se prohíbe en general que lleven los nombres de su gentilidad o superstición y se ordena que a todos se les impongan en el bautismo los nombres cristianos habituales que han de conservar también entre ellos. Para distinguirse unos a otros, han de conservar los apellidos, paternos los varones y maternos las mujeres. (Lisi 1990: 133)

De esa manera, los indígenas serán bautizados con nombres occidentales (Sebastián, Miguel) y sus nombres de origen prehispánico se convertirán en sus apellidos; así se registra, por ejemplo, en el testamento de Antonio Chumbi Guamán (Mansiche, 13 de setiembre de 1679), donde además se sigue la costumbre española de apodar 'el Viejo' al padre, para no confundirlo con su hijo, quien pudiera llevar el mismo nombre y apellido:

(a) "Yten declaro otra suerte de tierras más arriba, que está habido pleito con don Sebastián Guamán Chumo” (Vega Cárdenas 2008). 
(b) "tengo otra suerte de tierras llamadas Balmini en el valle de Nasape y por otro nombre Conache, como parecerá por la ejecutoria, que lindan con las tierras de Miguel Guamán Chumo, el Viejo" (Vega Cárdenas 2008).

Finalmente, ambos vocablos huaman y chumo quedarían con el paso del tiempo fusionados en una sola palabra, puesto que, contrario al uso español, no se trataba de un apellido materno y otro paterno, sino que se tomaría como apellido de un único cacique y de su descendencia: Huamanchumo.

\section{A modo de propuestas}

No sólo la lectura curiosa de textos historiográficos en torno al descubrimiento y conquista del Perú, sino la revisión especializada de documentos almacenados en diferentes archivos históricos, resultan motivadoras para iniciarse en los caminos de la Onomástica de antropónimos prehispánicos; sin embargo, tarea necesaria constituiría todavía indagar entre los no tan viejos registros de inmigrantes chinos y japoneses, por ejemplo; o emprender la investigación de campo entre las lenguas ágrafas que aún perviven en las regiones amazónicas de nuestro país. En la medida en que se conozca la naturaleza plurilingüística que se esconde detrás de tantos apellidos peruanos -como es el caso del nombre revisado en este nota-, se podrá reconocer la importancia de este tipo de estudios como aporte decisivo para la ampliación de los criterios de fundamentación en cualquier ciencia humana que se encargue del estudio de la cultura peruana. 


\section{BIBLIOGRAFÍA}

ACOSTA, Padre Joseph de. Historia Natural y Moral de las Indias. México, Buenos Aires, 1962.

BETANZOS, Juan de. Suma y Narración de los Yngas [1551]. Madrid, Atlas, 1987.

CABELLO VALBOA, Miguel. Miscelánea Antártica [1586]. Lima, Instituto de Etnología, 1951.

RECOPILACIÓN Recopilación de Leyes de los Reynos de las Indias.. [Recopilación de Leyes de los Reynos de las Indias, mandadas imprimir y publicar por la magestad católica del Rey Don Carlos II. Nuestro Señor. Madrid, 1791] Tomo II. Madrid, Consejo de la Hispanidad, 1943.

CARRERA, Fernando de la. Arte de la lengua Yunga [1644]. Tucumán: Radamés Altieri, 1939.

CERRÓN-PALOMINO, Rodolfo. La lengua de Naimlap (Reconstrucción y obsolescencia del mochica). Lima: F.E. P.U.C.P. , 1995

CIEZA DE LEÓN, Pedro. La Crónica del Perú. Colección Crónicas de América, 4. Manuel Ballesteros (Ed.). Madrid, Historia 16, 1985.

DÁVILA HERRERA, Carlos. "Presencia y Vigencia Mochicas”, en: Diario El Peruano. Sección 'Tribuna Libre'. 05. Set. 2001.

DE LA VEGA, Inca Garcilaso. Comentarios Reales de los Incas. Tomos I, II, III. Lima: Ed. Universo, 1980.

KAUFMANN DOIG, Federico. "El Perú Antiguo”, en: Historia General de los Peruanos - Tomo I. Lima: Peisa, 1979. 
LAFAYE, Jaques. Los conquistadores. Figuras y escrituras. México D.F. : F.C.E., 1999.

LEVILLIER, Roberto. Gobernantes del Perú. Cartas y papeles. Siglo XVI. Tomo I. Madrid: Sucesores de Rivadeneyra S.A., 1921.

Ordenanzas de don Francisco de Toledo (1569 - 1581). Madrid: Imprenta de Juan Pueyo, 1929.

MAYER, Eugen F. Chan-chan. Vorspanische Stadt in Nordperu. München: Verlag C.H. Beck, 1982.

MIDDENDORF, Ernst W. "Muchik" (Traducción del Cap. III de Die Einheimische Sprachen Perus.) Lima: s. i. , 1959.

SARMIENTO DE GAMBOA, Pedro Historia de los Incas. Siglo XVI. Buenos Aires: Emecé Editores, 1942.

ORÉ, Luis Gerónimo de. Rituale seu Manuale Peruanum [...]. Neapoli: Jacobum Carlinum et Constantino Vitalem, 1607.

VEGA CÁRDENAS, Carlos Alberto y Miguel Adolfo. "Testamento de Antonio Chumbi Guamán, Principal del pueblo de San Salvador de Mansiche". Historia Documental de Trujillo, en <http://historiadocumentaldetrujillodelperu.blogspot. $\mathrm{com} / 2008 / 12 /$ testamento-de-antonio-chumbi-guamn. html>, 04. Julio 2009.

ZEVALLOS QUIÑONES, Jorge. Cacicazgos de Trujillo. Trujillo: Gráfica cuatro S.A., 1992.

\section{Correspondencia:}

Ofelia Huamanchumo de la Cuba

Ludwig-Maximilians-Universität München

Correo electrónico: ofeliahde@yahoo.com 